\title{
Mathematical practices and mathematical modes of enquiry: same or different?
}

Hamsa Venkat ${ }^{1,2}$

\begin{abstract}
Background: In this paper, I share a case study of a teacher's work on mathematics tasks in the context of a 'mathematics for teaching' course aiming to develop mathematical content understandings and mathematical practices among primary teachers in one South African province. The course was developed in a national context of concerns about the nature and levels of primary teachers' mathematical knowledge. Theories viewing mathematical practices as fundamental, contrasted with those that view mathematical practices and mathematical content in more separate and 'to be integrated' ways, are used to frame the analysis and critically reflect on the findings.

Results: Data from this teacher's pre-test and selected course assessments and interactions suggest that while he was able to develop some aspects of the mathematical practices described in the literature, his overall orientation remained attuned to memorization and recall. Findings also pointed to an ongoing reliance on external validation of the 'correctness' of his answers.

Conclusions: The data suggest that the presence of elements of mathematical practices cannot be viewed as equivalent to the presence of mathematical modes of enquiry. The analysis presented in this paper suggests that while elements of mathematical practices can be developed, moving towards an encompassing orientation to mathematical modes of enquiry may require more central focus on problem-solving approaches to achieve a change in orientation.
\end{abstract}

Keywords: Mathematical practices; Mathematical modes of enquiry; South Africa; CCSM; Primary mathematics

\section{Background}

A significant body of writing in mathematics education points to the importance of mathematical processes/practices within mathematical working. Writing focused on the nature of mathematics has noted its 'autopoeitic' form, in that mathematics produces the objects it discusses, rather than describing objects or phenomena that exist externally in the physical world (Sfard 2008; Maturana and Varela 1980). A consequence of this view of the nature of mathematics is that the production of mathematical objects in non-mathematical ways produces a discourse that fundamentally disrupts the nature of mathematics as a discipline.

So what are considered to be mathematical practices? These practices have been described in a number of

\section{Correspondence: hamsa.venkatakrishnan@wits.ac.za}

${ }^{1}$ Wits School of Education, University of the Witwatersrand, Johannesburg, South Africa

${ }^{2}$ Wits School of Education, University of the Witwatersrand, Johannesburg, South Africa and Jönköping University, Jönköping, Sweden ways at more general and specific levels. The National Council of Teachers of Mathematics (NCTM), for example, described general mathematical processes in terms of representing, problem-solving, reasoning, connecting, communicating - with all of these acting as means of mathematizing (NCTM 2000). More specific descriptions of mathematical practices include attention to, e.g., ordering, structuring, reversing, abstracting, and generalizing (Mason et al. 1982).

In recent years, there has been an overt emphasis on incorporating attention to mathematical practices alongside content in many curricula, (e.g., NCTM 2000 in the United States). The ongoing emphases on coverage and accountability, though, continue to be reflected in concerns that mathematics is presented as its content-based 'products' rather than in terms of its processes leading to products.

In the South African context of this paper, postapartheid curricula that placed greater emphases on mathematical practices have given way to a reversal back 
to more traditional content specifications. A key driver for this reversal was extensive evidence of gaps in teachers' content knowledge which, in the terrain of the less explicitly specified and process-orientated versions of curricula, contributed to pedagogies that were criticized as mathematically hollow. This evidence on teachers' mathematical content knowledge, much of it focused on primary level mathematics, suggests gaps at or close to the level at which they are teaching (Carnoy et al. 2008; Taylor 2011). There is evidence too, though, of pedagogic shortcomings at the level of mathematical practices rather than at the level of content (Venkat 2013). These concerns are set within broad national and international acknowledgement that teachers are reproducing trained ways of working, with the added awareness in South Africa of a history of inequitable and disrupted access to education for the majority of teachers currently in the system.

In exploring mathematics teacher learning for teaching, Watson and Barton (2011) suggest a 'fundamental' view of mathematical practices in which 'mathematical modes of enquiry' are central:

'Knowing mathematics means being able to use mathematical concepts mathematically: the two cannot be separated'. (p. 66)

This fundamental view is contrasted in this paper with views that identify content and practices in what I describe as more 'separate but to be integrated' ways.

Within our work in the Johannesburg-based Wits Maths Connect-Primary (WMC-P) research and development project, we developed a 'primary mathematics knowledge for teaching' course that incorporated attention to mathematical practices within a structure that was delineated on the basis of broad content areas. The course consisted of 16 contact days spaced across the school year in 2-day blocks, with each block focused on a content area - e.g., numbers and number system, additive relations, multiplicative relations, etc. Our attention to mathematical practices was embedded within an overt framework based on developing teachers' awareness and explanations in relation to mathematical content areas, reflecting more the 'separate but integrated' position.

Work with teachers across three cohorts (2012-14) has indicated broad successes at the level of content knowledge gains (based on pre- and post-test results with each cohort) and in relation to some of the mathematical practices referred to above (based on course task assessments that placed emphasis on problem-solving through connecting, representing, communicating, and explaining). The successes were not universal though and led to the question driving this paper: the extent to which separate but integrated views of mathematical practices and content can be considered as consistent with or equivalent to the notion of mathematical modes of enquiry. This issue is explored through a focus on a teacher (Christopher, pseudonym) whose interactions and test performance indicated moves towards aspects of some mathematical practices but set within an overarching orientation that remained at some distance from mathematical modes of enquiry. Through looking at some of Christopher's task responses and interactions, I analyze instances of both his use and disruption of mathematical practices. I suggest that underlying the somewhat contradictory nature of his working is a failure, on our part, in shifting Christopher's overarching orientation to mathematics towards one that could work mathematically with mathematical objects. Rather, he maintained an orientation to mathematics that was about remembering and retrieving facts and processes, even while showing some evidence of being able to engage in reasoning and problem-solving activities.

Christopher's story takes current understandings of the development of mathematical practices in pedagogy forward in two ways. Firstly, it adds to the relatively limited body of knowledge that has explored shortcomings relating to mathematical practices within pedagogy providing exemplifications of how these limitations play out. Secondly, it allows for a critical consideration of different theorizations of mathematical practices in relation to mathematical content. Christopher's story suggests that our more 'separate and integrative' presentation of mathematical content and practices was not sufficient for eliciting broad-ranging moves towards mathematical modes of enquiry within the time frames that we had available.

Christopher's story is shared through the following structure: the paper begins with a literature review outlining the nature of mathematical practices and reasons for their advocacy. South African data that suggest some distance from mathematical practices, as vehicles for carrying and producing mathematical objects, are then shared. The data sources and case study methodology drawn on for sharing Christopher's story are detailed and followed by a section where his responses on key tasks and accompanying interactions are presented and analyzed. I conclude the paper by considering what this analysis suggests for ways of thinking about developing mathematical practices.

\section{Mathematical practices - a literature review}

Attention to mathematical practices continues to get wide attention in the international mathematics education literature. Writing emanating from the United States has been particularly influential in this regard. The current 'common core standards for mathematics' (CCSM) (Common Core State Standards Initiative 2010) 
include a set of 'Standards for Mathematical Practices'. This set, drawing from the NCTM list stated earlier and Kilpatrick et al. (2001) 'strands of mathematical proficiency', contains the following features:

- Make sense of problems and persevere in solving them

- Reason abstractly and quantitatively

- Construct viable arguments and critique the reasoning of others

- Model with mathematics

- Use appropriate tools strategically

- Attend to precision

- Look for and make use of structure

- Look for and express regularity in repeated reasoning (pp. 6 to 8 )

Each of these practices has an extensive associated literature base. In this overview, I provide some detail on aspects of the practices that are relevant to issues that have been raised in the South African teaching landscape (and thus to our work within the course) and to the empirical data that follows.

\section{Problem-solving}

Polya's (1962) early but seminal work on problemsolving continues to be widely cited in the literature. Polya emphasized the importance of starting with situations that provide an authentic problem - a problem for which solution procedures are not known at the outset and have to be developed. The CCSM document reflects this notion, describing sense-making/problem-solving proficiency in terms of understanding problem situations in terms of 'givens, constraints, relationships, and goals' (p. 6), with this understanding, feeding in to the formulation of possible solution pathways.

\section{Abstract/quantitative reasoning}

Mason has written extensively about the nature of abstract reasoning and abstraction within mathematical working (e.g., Mason 1989). Working with abstract reasoning as a follow-up to generalizing activity, Mason describes these two practices as collectively representing a move from 'manipulating objects (physical, pictorial, symbolic, mental) to expressing properties or features of those objects in ways that can form the basis for further manipulations' (p. 3). Sfard's (2008) notion of mathematics developing through the production of 'discursive layers' provides a more condensed version of these processes. Schifter (2011) explains her emphasis on teaching driven towards helping children to reason quantitatively through considering the effects of operations on numbers, rather than practicing operational procedures through lists of calculations. Across this writing is a view of mathematical learning guided by the need to move beyond getting the answer to the immediate problem, to being able to abstract structural similarities between situations that allow for the generation of increasingly powerful, generalized problem-solving techniques.

\section{Constructing viable arguments}

The need to construct viable arguments draws from Kilpatrick et al. (2001) 'adaptive reasoning' strand. It involves developing the capacity to build networks of logical statements - argumentation chains with awareness of the warrants that underlie them. Over time, and through experience of the breadth and boundaries of associated example spaces, this standard also calls for awareness of the 'domains to which an argument applies'. Yackel (2001) notes that within teaching for the development of justification and argumentation practices:

'initially children had to learn that their explanations and justifications needed a mathematical, rather than a social, basis'. (p. 14)

Kazemi and Stipek (2001) contrast teachers' orchestration of 'mathematical arguments' with 'procedural descriptions', associating the former with classrooms characterized by a 'high conceptual press' and the latter with 'low conceptual press'.

\section{Mathematical modeling}

A key antecedent for emphasis on mathematical modeling is the Dutch work on 'Realistic Mathematics Education' (RME). A central assumption within RME is that mathematics emerges, or comes to be reinvented, through mathematization activity that seeks to understand and organize phenomena (Freudenthal 1983). Interpreting results in relation to the situation also features within this standard.

\section{Mathematical structure and regularity}

Attunement to noticing patterns and structure is a key part of the 'looking for structure' strand. Attention to juxtaposing examples in ways that draw attention to variations, invariances, and connections between examples has been argued as one way to develop this attunement (Watson and Mason 2006). Careful sequencing can draw attention to ideas like 'doing and undoing' and the regularities within sets of related examples in ways that draw attention to underlying mathematical structure.

\section{Is attention to mathematical practices necessary?}

At one level, the thrust of much of the work on mathematical practices appears to state the obvious, like Watson and Barton's (2011) emphasis on using 'mathematical concepts mathematically'. This view fails however to explain the 
ongoing attention to mathematical practices in the literature. In order to understand this emphasis, we need to seek out the phenomena within mathematics teaching and learning that have motivated these foci. To do this, I return to the writings mentioned above to note the shortcomings that their attention to mathematical practices seeks to address. This is followed by an outline of South African evidence on mathematics teaching and learning related to mathematical practices that led to the choice to orient our primary mathematics knowledge for teaching course in particular ways.

Polya's interest in problem-solving heuristics was driven by observations of the absence in much of mathematics teaching of genuine problems - problems set, not with the intention of repeatedly practicing a previously taught procedure, but instead, problems for which a solution path is not known:

'to have a problem means: to search consciously for some action appropriate to attain a clearly conceived, but not immediately attainable aim. To solve the problem means to find such action'. (p. 117)

Mason (1989) highlights the difficulties that students often have with abstracting and generalizing in mathematics. He speculates that these difficulties may relate to the frequent presentation in mathematics lessons of abstract forms, divorced from the generalizing and abstracting activities that have produced them: 'there is a huge difference between expressing your own generality and doing someone else's algebra' (p. 3). Freudenthal (1973) takes this issue as the central pedagogic problem of 'anti-didactical inversion' wherein 'ready made' models that have emerged from the 'crystallized' products of prior mathematical activity are presented to children without giving them any access to the problems that produced them, nor to the contours of the models and the purposes that they are useful for. The need for a mathematical working guided by mathematizing activity is thus foregrounded in this literature.

Moving beyond generalizations and models more broadly into mathematical learning, Vinner (1997), p. 101 contrasts 'conceptual' and 'analytical' behaviors with 'pseudo-conceptual' and 'pseudo-analytical' behaviors:

'In mental processes that produce conceptual behaviors, words are associated with ideas, whereas in mental processes that produce pseudo-conceptual behaviors, words are associated with words; ideas are not involved'.

Vinner is careful to distinguish between pseudoconceptual modes of thinking and misconceptions, noting that the latter have definite cognitive involvement while the former are characterized by the lack of cognitive involvement. He argues that pseudo-analytical ways of working primarily involve reactions to stimuli or cues, rather than cognitive engagement (Vinner 1997, p. 121). Of interest in relation to the analysis that I present later is Vinner's acknowledgement that pseudo-conceptual behavior still involves attention to similarities between situation and model and between different task situations and their associated procedures. The problem is that these practices play out in ways that ignore logical reasoning chains or violate definitions. Superficial similarities, rather than similarities that are critical features of the topic or concept being handled, are instead noticed and followed up.

This brief overview highlights that the notion of working mathematically with mathematics, far from being an underpinning fundamental of school mathematical activity, is considered rather rare. A key outcome of Vinner's pseudo-conceptual orientations to mathematics is a heavy reliance on memorizing associations between perceptual features of situations and use of specific and localized procedural responses.

\section{South African evidence on primary mathematics teaching}

The South African landscape reflects the concerns identified above, sometimes in quite extreme forms. The terrain is marked by low performance in mathematics at all levels of schooling. In primary mathematics, substantial gaps between the advocated curriculum and attainment of large numbers of children are apparent by the end of grade 3 (DBE 2013). As noted already, larger scale studies have pointed to serious gaps at the level of teachers' mathematical content knowledge, with some of these studies showing gaps at or very close to the levels at which these teachers are teaching (Taylor 2011; Carnoy et al. 2008). Highly procedural orientations to teaching with lack of incorporation of problem-solving tasks have also been noted in teaching in the intermediate grades (grades 4 to 6) (Ally and Christiansen 2013; Sorto and Sapire 2011).

Smaller scale qualitative studies have investigated the nature of pedagogy. Hoadley (2007), using sociological lenses, drew attention to classrooms in which no criteria for the appropriateness of answers were provided. Adler and Venkat's studies have focused attention on the teachers' explanations, set within what they have termed teachers' 'Mathematical discourse in instruction' (MDI). While some of their episodes indicate breakdowns between tasks and representations (Venkat and Adler 2012), Adler and Venkat (2014) also draw attention to narratives that reflect 'ritualized' activity (drawing on Sfard 2008) in which:

'Talk is about actions on discrete symbol parts, and these processes are asserted, with substantiation that relies on perceptual features'. (p. 144) 
Across Hoadley's work and Adler and Venkat's papers, we see patterns of working in which mathematics is often produced and proceeds in the absence of mathematical argumentation. This teaching embodies many of Vinner's (1997) characterizations of pseudo-conceptual behavior, and Adler and Venkat (2014) note that such behaviors within learning reflect what is enacted in teaching:

'what is made available to learn through the teacher's MDI, and the substantiating narratives at work, relies on memory and visual cues'. (p. 144)

Venkat (2013) identifies instances where correct answers are produced in classroom teaching but in ways that disrupt notions of mathematical practices leading to the production of mathematical outcomes and objects. Her illustrative examples indicate a lack of attunement to how givens and unknowns are configured within problem-solving practices. Verificational processes occur in the absence of a preceding derivational process. Possibilities for students to independently produce correct answers to similar questions are severely disrupted here, with trial-and-error guessing representing the only option for pupils who do not know the answer at the outset.

\section{Theorizing integrative views of mathematical practices}

In the opening section, I contrasted a 'fundamental' view of mathematical practices with a 'separate but to be integrated' view of mathematical content and practices. The CCSM, in their separate listing of content and practice standards, tend to fall into the latter category. Further supporting this position is that while the CCSM document stresses the need to connect practice and content standards within teaching (p. 8), it suggests also that content standards containing the word 'understand' provide particularly fertile ground for such integration. This points to a more selective integration than the position proposed by Watson and Barton (2011), who offer a more fundamentally integrative view, with particular interests in mathematics teacher knowledge and education. They emphasize that mathematics teaching activity should center around enacting mathematics and that 'mathematical modes of enquiry' are central to this enactment. A consequence of this orientation for them is that discussions about what teachers of mathematics know cannot be divorced from the ways in which they know mathematics:

'It is not just a question of what teachers know, but how they know it, how they are aware of it, how they use it and how they exemplify it'. (p. 67)
Differences in the descriptions of mathematical practices in the 'separate but integrated' view and the 'mathematical modes of enquiry' view point to subtle differences in how mathematical working is conceptualized. In the CCSM view, mathematical practices are viewed as an outcome of well-connected understanding of content (p. 8). Mathematical modes of enquiry, in contrast, tend to point to mathematical practices as fundamental to developing mathematical understanding.

It could be argued that there is not really a distinction here between the more separate integrative (CCSM) and more fundamental (Watson and Barton) views; rather, the issues and gaps seen in mathematics teaching and learning lead to the need to make visible the mathematical practices that seem to 'fall out' of enactments of mathematics in classrooms. Listing practices separately from content, as in the CCSM formulation, provides one way of highlighting mathematical practices and drawing attention to their nature and range. Watson and Barton (ibid), however, tend to disagree with this view, arguing that curriculum lists are: 'hypothetical until mathematical modes of seeking, using, and exemplifying understanding are understood' (p. 66). Schoenfeld's (1987) attention to mathematical problem-solving echoes the fundamental view, with mathematical enactment, in his view, connected to developing capacities that link discourses, activities, and identities within a mathematical culture wherein mathematics functions as the medium of exchange' (p. 213).

In the next section, the teacher development course model is outlined and critically considered in terms of its orientation towards mathematical practices.

\section{The course model and orientation}

The South African evidence on content knowledge gaps and the nature of primary mathematics classroom teaching led to our development of a 'primary mathematics knowledge for teaching' course. As noted already, each 2-day block across the 16 contact days was focused on a content domain, with mathematics homework and classroom teaching tasks completed between contact sessions. While course pre- and post-test assessments featured items drawn from prior studies focused on conceptual understanding of key mathematical ideas, in-course assessments incorporated attention to constructing and communicating mathematical arguments within problem-solving and using emergent representations to model situations in ways that would allow for purposive selections of operations, rather than guessing or recalling the operations required. These latter tasks reflected multiple elements of the mathematical practices highlighted in the literature section above. 
I noted in the introductory sections that gains at the level of content knowledge and mathematical practices were seen in our assessments across three cycles of the course (2012-14). Teacher evaluations of the course suggested awareness of better understandings of content and growing awareness of the need for at least some of the mathematical practices noted in the literature review above. Learning related to explaining 'why' steps work was one of the most common comments on teacher feedback, alongside comments on learning related to specific content/representations/procedures. This feedback suggested some successes in making mathematical practices 'visible' in the course alongside mathematical content, while reflecting also the 'separate and integrative' position seen in the CCSM, rather than Watson and Barton's fundamental position on mathematical modes of enquiry.

\section{Methods}

A case study design is used in this paper. The case in focus relates to excerpts of mathematical working and accompanying talk on tasks completed by a teacher, Christopher, who was a course participant in 2013. The case is framed thus because the ways in which mathematical practices and/or mathematical modes of enquiry played out within this dataset was the 'phenomenon ... in a bounded context' (Miles and Huberman 1994, p. 25) that I was interested in. Christopher was not teaching mathematics in school in 2013 but was interested in doing so. Selected excerpts of his work from across the year and my fieldnote records of his commentaries and our interactions around this work are drawn on within the analysis. Christopher was an enthusiastic and vocal participant in our course sessions and was quickly willing to admit that while he often knew what to do, he frequently did not have any reasons for why he was performing the selected sequence of steps - redolent of Skemp's (1976) 'instrumental' understanding. Christopher's enthusiastic participation means that we have more evidence from him in terms of verbal commentary and interaction around his work than for most of the other teachers on the course, leading to my selection of him as a particularly illustrative or 'telling' case (Mitchell 1984). However, comments from other teachers suggest that the phenomena that he provided a case of - the ability to produce and expand a repertoire related to some mathematical practices without an overall shift in orientation towards mathematical modes of enquiry - were more widespread.

Christopher was teaching social science, natural science, and technology in grades 6 and 7 in a suburban primary school in Johannesburg. Christopher told us that he came on to the course because he was interested in teaching mathematics but had not done so previously.
His academic background (a BA Honours degree in Education) represented a higher level of education than many of his peers, and his pre- and post-test scores were above the cohort's mean scores in both tests.

The data I draw on to analyze Christopher's mathematical working are drawn from three points in the year. The first excerpt of his working is on an item in the pretest. The second excerpt, drawing on his workings and his commentary and interactions on this working, occurred halfway through the course in the context of an assessment focused on multiplying decimals. The third excerpt is also located in his working and related commentary (recreated from my fieldnotes in this case) and is drawn from an additional voluntary revision session that we offered at the end of the year before the final post-test where participants were asked to bring problems that they had tried and were having difficulty with. Broader background data on Christopher's performance are drawn from the datasets that we keep for all the teachers detailing their performance across all course tasks. These data are selected because they are usefully illustrative of 'recurring regularities' (Guba 1978, p. 53) in Christopher's responses at points when he was not completely certain of the procedure being worked with. As noted already, sporadic responses from other teachers across all three years indicate that presences of aspects of mathematical practices allied with absences in relation to an overarching orientation to mathematical modes of enquiry were more broadly prevalent.

My analysis of this data links to interpreting presences and absences in relation to the literature-based identification of markers of mathematical practices overviewed earlier. Ethical clearances for data collection, analysis and anonymized reporting in the course were granted by the university and the provincial education department, with informed consents for use of course-related data for research purposes granted by participating teachers.

\section{Results and discussion}

\section{Excerpt 1}

While Christopher's performance on the pre-test indicated that he was well above the group mean in terms of his mathematical content knowledge, his ways of working indicated an orientation that swung towards operational techniques more often than towards structure or generality. For example, three items on the pre-test, shown in Table 1, were focused on using rounding to estimate answers to decimal multiplication and division calculations:

Christopher had circled the correct answer in all three cases. His work on these three problems (scribbled on a rough piece of paper inside his test script) is shown in Figure 1. 
Table 1 Pre-test items

Circle the number that is nearest in size to the answer (do not work out the answer)

\begin{tabular}{llllllll}
\hline $2.9 \times 7$ & 0.002 & 0.02 & 0.2 & 2 & 20 & 200 & 2000 \\
$0.29 \times 7.1$ & 0.002 & 0.02 & 0.2 & 2 & 20 & 200 & 2000 \\
$59 \div 190$ & 0.003 & 0.03 & 0.3 & 3 & 30 & 300 & 3000 \\
\hline
\end{tabular}

This work shows that for questions 1 and 2, in contradiction to the instruction, Christopher calculated actual answers using traditional column multiplication methods (with an error in the second calculation) and then rounded. The work seen on the third problem is interesting because Christopher tried two related problems $(190 \div 59$ and $590 \div 190)$ and used repeated addition to get 3 as the rough answer for both of these problems. The correct approximate answer (0.3) is written below but whether this was arrived at through an awareness of reciprocal or scaling down relationships, or simply by guessing, is not known.

Part of the complexity of Christopher's orientation is that his work indicates that he has at least some of the quantitative reasoning skills needed to work out the answers to the first two problems by rounding (e.g., he is able to round his answer of 20.3 correctly to 20). The issue here is not that he does not know how to round off to the nearest whole number. Instead, it would appear that the presence of a problem in mathematics is viewed as a trigger for a calculation, regardless of an instruction that calls for a solution through quantitative reasoning. The instruction is returned to after the exact answer has been calculated. This routine is followed in the second example as well, where, in spite of a calculation error, his answer still takes him to 2 as the nearest answer. Thus, while relevant reasoning practices are sporadically evident here relating to rounding and possibly scaling up and reversing downwards, these are not set holistically within either the quantitative reasoning
(Schifter 2011) or the strategic working (Kilpatrick et al. 2001) that are described as part of the mathematical practices canon or mathematical modes of enquiry frame.

In Christopher's response to the third question, his selection of two associated, simpler calculations suggests some awareness of quantitative relations. I cannot tell from the marks on the paper whether Christopher used scaling down to get from 3 to 0.3 , mirroring the relationship between 590 and 59 . What we can see is that this technique was not brought into play in question 2, where it could also have been applied. In combination, a highly localized approach to techniques is seen and further, thinking about quantitative relations appears to come into play only when a procedure is not immediately at hand, pointing to a prioritization of content and techniques over a more fundamental integration of mathematical modes of enquiry. Thus, the evidence taken together indicates a lack of consistent attunement to reasoning quantitatively, rather than an inability to do so.

\section{Excerpt 2a}

The second excerpt relates to Christopher's responses and interactions on a decimal multiplication task halfway through the course. The course was structured such that the topic in focus in each 2-day block had a short assessment associated with it in the following 2-day block. Days 5 and 6 had been focused on multiplication and division. Various models for representing multiplication and division situations had been discussed during the 2 days, with 'area' models of multiplication developed out of more basic array models in the context of early multiplication. The assessment on day 8 included the question shown in Figure 2.

Christopher's solutions to this particular set of problems are shown in Figure 3. This work followed a word problem asking for the area of a rectangular field
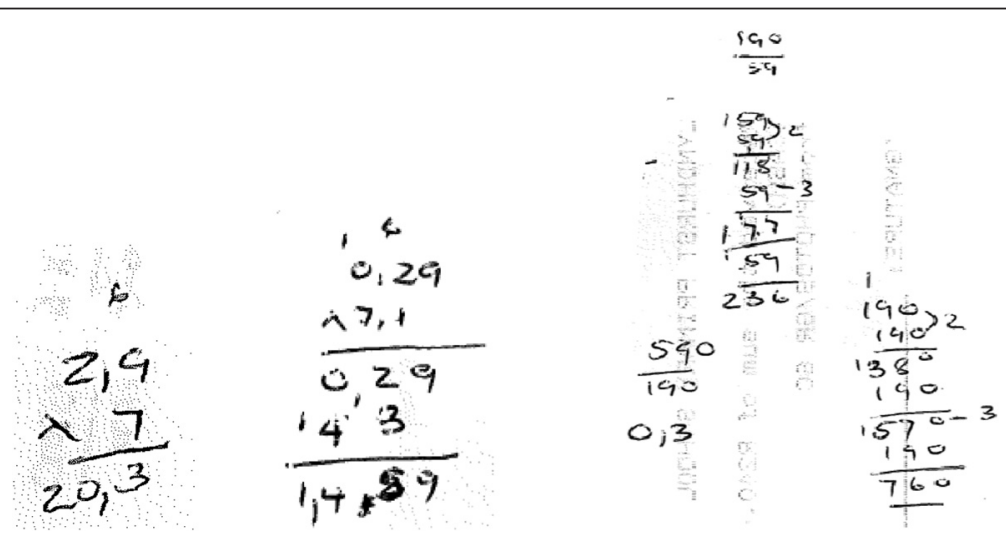

Figure 1 Christopher's working on Table1 pre-test items. 
involving two integer value dimensions. Christopher had calculated the answer to this first problem correctly using a traditional column algorithm method.

\section{Discussion 2a}

We see here and following from the work seen above in the pre-test that Christopher appears to have difficulty with multi-digit long multiplication involving decimal numbers. The consistency in his problem setup indicates fragments of remembered rules - 'the decimal point has to line up', 'move a column across each time you deal with a new partial product', and 'the number of digits after the decimal point is the sum of the number of digits after the decimal point in the numbers being multiplied'. However, 'carrying' within the partial products appears haphazard - sometimes applied and other times missed. As in his pre-test working, his exact answer (incorrect) is rounded for the estimate, in spite of the repeated addition of 13 three times alongside the calculation.

Beneath the request for an area method, there is an attempt at some elements of the 'form' that accompanies area models - a grid that looks like a table. However, the partitioning of number that can be used within areabased models is absent, and instead, his own long multiplication column model is placed within the grid. Alongside this diagram, the calculation above is repeated with the same incorrect answer. Here, the association of the area model with the visual grid format is evident and points to the pseudo-conceptual behaviors described by Vinner (1997).

\section{Excerpt 2b}

In the course, we follow interim assessments with a subsequent feedback session where common errors, misconceptions, or shortcomings are discussed. A follow-up repeat opportunity to do a similar task is offered. In Christopher's case, the repeat assessment was on day 9 of the course (about a month after the earlier task). The repeat assessment task involved calculating the area of a strip of field $42.5 \mathrm{~m}$ long and $2.15 \mathrm{~m}$ wide. While completing this task, Christopher called me over. He asked me to look at his written script - which, at this point, contained the working shown in Figure 4.

In his working, two models had been juxtaposed alongside each other - the area model on the left and a column algorithm model placed within a place value frame. The answer for his area model working was written in the middle of the page $\left(91.375 \mathrm{~m}^{2}\right)$. His answer for the column model working was 9,137.50. Christopher had noticed that the two answers were different and was perturbed enough to call me over. Our conversation proceeded thus:

Hamsa: Yes?

Christopher: There's a problem here.

Hamsa: Oh, what?

Christopher: See this, there are two different answers.

Hamsa: Yes, I see. Is that a problem?

Christopher: Yes, they should be the same.

Hamsa: Ok. And they are not. So is one of them right and not the other?

Christopher: Yes, but I don't know which.

Hamsa: So how could you decide?

Christopher: I don't know. I've checked all the numbers on both sides. They are right.

Hamsa: So if we look at the question, roughly how big do you think that field should be? Do you think you could use that to help you decide?

I left Christopher at that point to carry on. In the version we took in, Christopher had added the line shown in Figure 5 to his working:

\section{Discussion $2 b$}

Several aspects of Christopher's work are of interest here. The first point is that he has expanded his representational repertoire to include the area model for the first time voluntarily in an assessment and used this model to calculate the correct answer. His writing above the models indicates also that he is strategically aware of the extent of scaling up required to move from 42.5 to

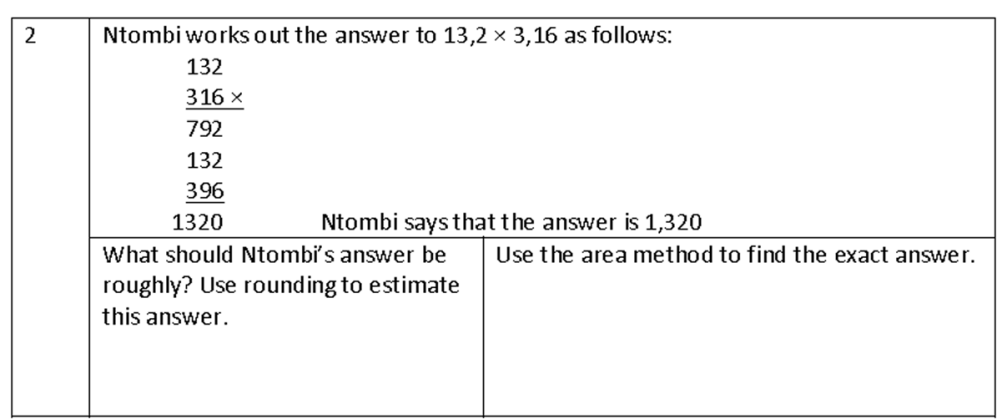

Figure 2 Day 8 assessment question. 


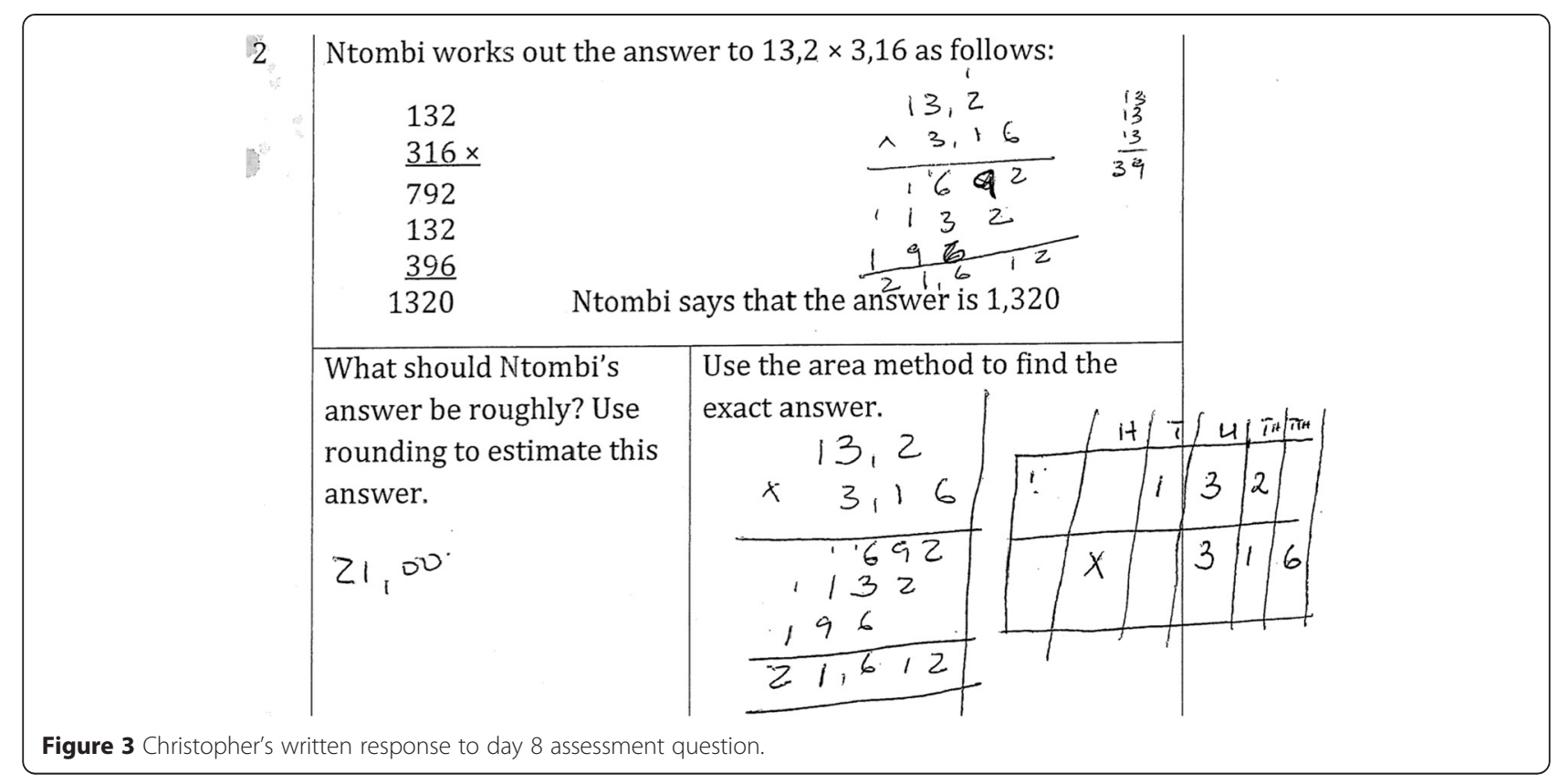

425 and from 2.15 to 215 , i.e., to produce a related integer value, with the reverse scaling down applied appropriately to the answer at the end. Strategic selections within problem-solving and awareness of how to reverse operational effects - highlighted as important aspects of mathematical thinking (Mason et al. 1982) both feature prominently within descriptions of mathematical practices.

However, Christopher appears to remain uncertain about this new method and repeats the calculation in column form. In placing the problem in a place value grid, he adds a ' 0 ' onto 42.5 to make 42.50 in the calculation. The carrying is error free here within all the partial products, but the decimal point is re-inserted in the wrong position in the bottom line. On completion,
Christopher's appeal to me for resolution coupled with the seeming absence of mathematical resources for dealing with two inconsistent answers indicates a lack of development of the sociomathematical norms (Yackel 2001) described as critical to mathematical enquiry. When a 'path' is suggested though, he is able to enact the calculation required with the rounded numbers and, on the basis of this, decides that his area model answer is the correct one. There is no mathematical curiosity though, to understand why or where the second method went wrong. Schoenfeld (1987) has noted that students holding beliefs about mathematics as devoid of meaningmaking frequently write contradictory statements in sequence. Christopher interprets the difference between the two answers as a problem. However, his resolution

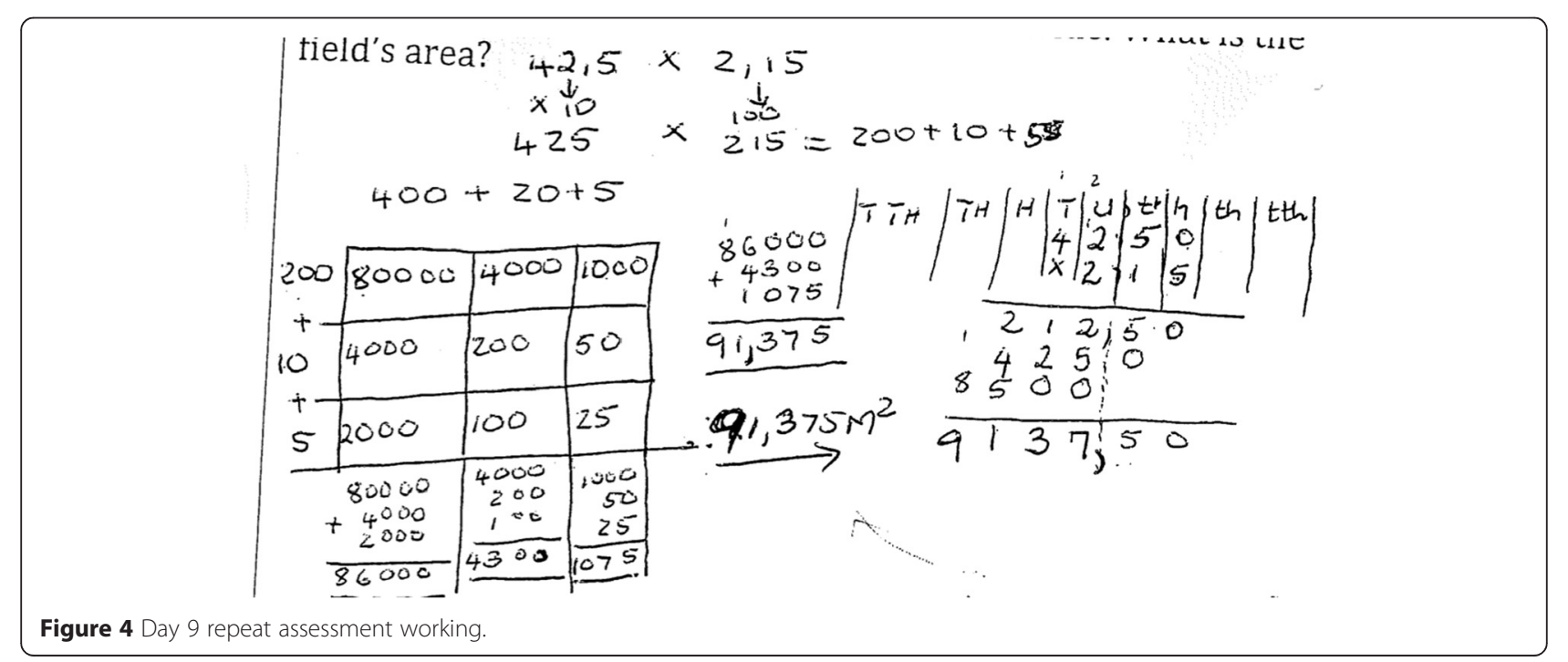




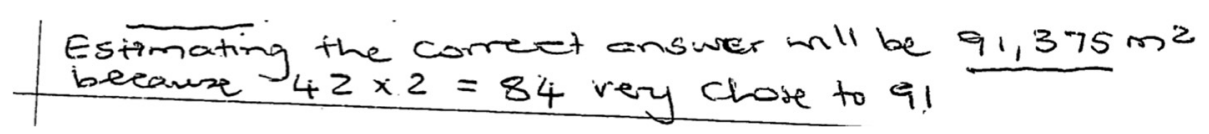

Figure 5 Added working.

remained reliant on external direction and ended with a decision on which answer was correct, without wanting to find out what was wrong with the rejected answer. Given the importance accorded to dealing with learner errors within the mathematics teacher knowledge literature (Ball et al. 2005), Christopher's lack of interest in probing his own mathematical error is particularly problematic. The disposition to view mathematics as reasonable is notably absent here, pointing to lack of shift in some aspects of mathematical practices in the midst of evidence of other elements.

\section{Excerpt 3}

The next excerpt is drawn from an optional additional revision session held towards the end of the year in early October, where teachers were invited to bring tasks that they had tried but were having difficulty with. One problem that some teachers asked for help with was the 'Hifives' task (Beckmann 2011) asking for the number of hi-fives needed between a group of 20 people if each one hi-fived everyone else. Our support consisted of prompts based on many of the problem-solving heuristics that Mason et al. (1982) and Schoenfeld (1985) have suggested:

Hamsa: 20 is quite a large number of people to work. Can we think about the situation with a smaller number of people to make it more manageable?

'Four people' was suggested. Four participants came up and acted the problem out, the first person hi-fiving the other three, the next hi-fiving the two that she has not hi-fived, and so on. We then 're-played' the actions with a mathematical representation for the number of hi-fives. The group told me that the total would be:

$$
3+2+1+0=\text { total number of hi-fives }
$$

They calculated this total by adding. I asked them to think about the situation for five people. In groups, with some acting out and some moving straight into the symbolic expression, all reached the expression $4+3+2+1$ +0 and calculated the answer. Returning to the original problem, most (including Christopher) were able to directly write down the expression representing the total number of hi-fives for 20 people as: $19+18+\ldots . .+1+$ 0 . Some started complaining that this was a very long sum to work out. Noting that part of working mathematically involves trying to find shortcuts for long-winded calculations, we ended up, after some discussion, with the annotated expression shown in Figure 6.

Some said that the ten groups of 19 in this list made 190 the total. Most seemed satisfied with this, but one teacher asked if the same method could be used for 15 people. I suggested they try this problem to decide if they could use the same method. Christopher was working with a group on this problem. After a spell working with his group, he asked me to look at his working - recreated from my notes (Figure 7).

Below, Christopher had written the following sequence of additions:

$$
\begin{array}{r}
14+0=14 \\
13+1=14 \\
12+2=14 \\
11+3=14 \\
10+4=14 \\
9+5=14 \\
8+6=14 \\
7+7=14
\end{array}
$$

Adding up the eight groups of 14, Christopher had arrived at 112 as his answer. His calling me was prompted by the fact that others in his group had a different answer: 105. Once again, there is evidence here of Christopher's ceding authority for 'correctness' to me as the teacher (after discussion with his colleagues here) - retaining Yackel's (2001) social, rather than mathematical, bases for judgment. Together, we traced through his connecting arrows over the total expression and linked them to the list of sums below - e.g., the 14 and 0 pair links to the $14+0$ sum. Reaching the 7 in the middle, I noted that there was only one 7 in his total expression but there was a $7+7$ (i.e., two $7 \mathrm{~s}$ in his list of sums). Christopher responded thus:

'Oh, so I must not have $7+7$. But you put an arrow over all the numbers in the list'.

Pointing to his working on the 20-person example, I responded that there had been two numbers in the middle in that case that I could connect.

Christopher nodded slowly and said: 'So if there is a number in the middle on its own, I don't put an arrow in the middle over it, I just add it on its own'. A colleague on his table interjected that odd numbers of people would leave a number on its own in the total expression. Christopher listened and responded: 'So I must remember 


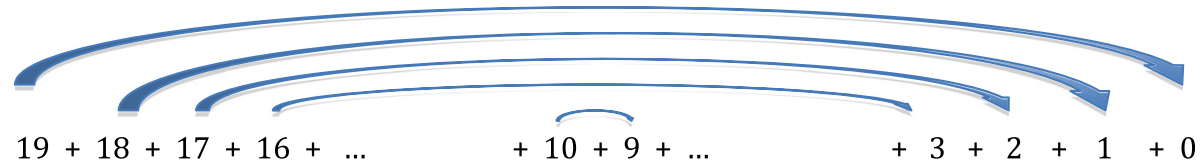

Figure 6 Annotated expression.

that odd numbers will leave a number on its own in the middle without an arrow and even numbers won't have a number on its own'. He annotated his working with the words 'Odd number' and underlined them. I ventured that as he had just figured the expression out, he probably did not need to commit this fact to memory. I noted later that he had annotated his earlier copying down of the answer for 20 people with the words 'Even number' underlined.

\section{Discussion 3}

Vinner's (1997) identification of attention to 'superficial similarity' within pseudo-analytical working is apposite here. Christopher's initial response, setting up the addition string for calculating the total number of hi-fives, shows evidence of some facility in construction of problem solutions through the initial setting up of an appropriate model. In making this construction, there is attention to the pattern seen in earlier examples and to generalizing what he has noticed to a new case. However, the need to make sense of this emergent representation and to attend to its structure in order to transform it appropriately are lost in his next steps, pointing to sporadic and partial presence of some mathematical practices. Christopher's attention is directed instead to incidental perceptual features - connecting arrows between terms in the numerical string, rather than the values they are connecting. His response to the discrepancy between his addition list and this numerical string illustrates his belief that he needs to remember what to do in the context of different cues. A dominant reliance on memory is therefore apparent in Christopher's comments and responses, again in the midst of indications that sensemaking is within his grasp.

\section{Conclusions}

The analysis suggests that the presence of, even multiple elements of, mathematical practices cannot necessarily be considered equivalent to take up of mathematical modes of enquiry. Christopher retains a view of mathematics as dependent on memory and external validation through instances of strategic adaptation and abstraction. Framing his recruitment of mathematical practices is a recurring incidence of working and interaction driven by the need to 'pin down' the procedure that will produce the answer, rather than attend to structure and sense-making. As Schoenfeld (1987) has noted, these ways of working with mathematics run concurrently, in many instances, with the underlying content knowledge needed to reason in the problem contexts described.

Empirically, this analysis suggests that presenting mathematical practices in terms of separate strands alongside content strands can create situations in which specific practices are produced but set within a broader orientation that remains procedure and answer driven. In this 'separate and integrative' frame, where mathematical practices are selectively, rather than fundamentally, drawn upon, it would appear that a possible outcome of sporadic absence of explicit attention to mathematical practices is the disruption of mathematical modes of enquiry. Watson and Barton (2011) might consider this outcome to be the consequence of failing to view mathematical modes of enquiry as fundamental to all mathematical working.

In the course teaching, while mathematical enquiry modes were never disrupted, they were not always centrally the focus of discussion and reflection. It could be the case that it is the limited timeframe of the course rather than the mode of engagement with mathematical practices that is critical. In any case, the evidence presented in this paper points at the very least to the need for greater attention to mathematical practices within our work with teachers. A concluding post-script supporting this conclusion came from another teacher who attended the course in 2014. Her performance on the

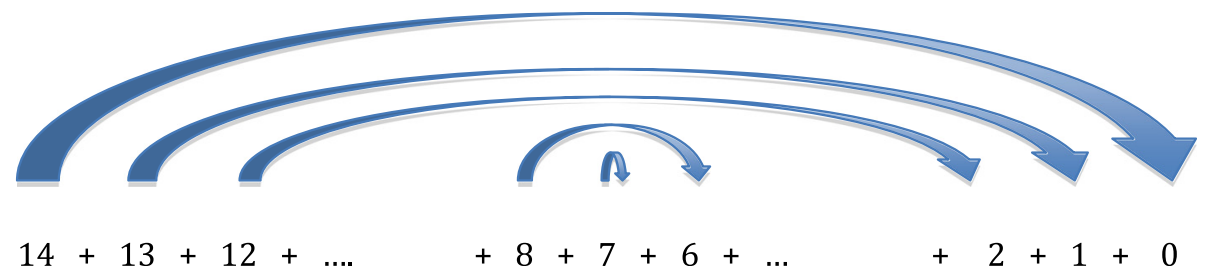

Figure 7 Christopher's working. 
pre-test was similar to Christopher's and her post-test score was higher than his. Like him, she was positive and enthusiastic about the course. In the 2014 late-year revision session, she offered an entirely coherent explanation of how to produce the 'rule' for a linear sequence, with the mathematical arguments that Kazemi and Stipek (2001) describe as important for a high conceptual press communicated across all her steps. Several of the mathematical practices detailed in this paper were marshaled within her problem-solving and associated explanation. She paused at the end, looking doubtful, and asked: 'Was that right?' While assuring her that it was, her response provided further support for the view that accretions of mathematical practices, even when enacted without the disruptions seen in Christopher's working and commentary, may yet not amount to a practice driven fundamentally by trust in mathematical modes of enquiry. The analysis suggests that while elements of mathematical practices can be developed, moving towards mathematical modes of enquiry may require more explicit, consistent, and longitudinal attention to problem-solving approaches to support orientational change.

\section{Competing interests}

The author declares that she has no competing interests.

\section{Authors' information}

HV holds the SA Numeracy Chair and leads the WMC-P project within which the data reported on in this study was collected. HV was also the coordinator and tutor, with doctoral students Lawan Abdulhamid and Samantha Morrison, on the 'mathematics for teaching' course that provides the context of this paper.

\section{Authors' contributions}

$H V$ is the sole author of this research article.

\section{Acknowledgements}

This paper forms part of the work in progress within the Wits SA Numeracy Chair project, entitled the Wits Maths Connect - Primary project. It is generously funded by the FirstRand Foundation, Anglo American, Rand Merchant Bank, and the Department of Science and Technology and is administered by the National Research Foundation.

Received: 4 September 2014 Accepted: 5 February 2015

Published online: 23 April 2015

\section{References}

Adler, J, \& Venkat, H. (2014). Teachers' mathematical discourse in instruction: focus on examples and explanations. In H Venkat, M Rollnick, J Loughran, \& M Askew (Eds.), Exploring mathematics and science teachers' knowledge: windows into teacher thinking (pp. 132-146). Abingdon, Oxon: Routledge.

Ally, N, \& Christiansen, I. (2013). Opportunities to develop mathematical proficiency in grade 6 mathematics classrooms in KwaZulu-Natal. Perspectives in Education, 31(3), 106-121.

Ball, DL, Hill, H, \& Bass, H. (2005). Knowing mathematics for teaching: who knows mathematics well enough to teach third grade, and how can we decide? American Educator, 29, 14-22.

Beckmann, S. (2011). Mathematics for Elementary Teachers with Activity Manual, 3rd edition: Pearson

Carnoy, M, Chisholm, L, Arends, F, Baloyi, H, Hoadley, U, wa Kiwilu, M, et al. (2008). Towards understanding student academic performance in South Africa: a pilot study of grade 6 mathematics lessons in South Africa. Pretoria: HSRC.

Common Core State Standards Initiative. (2010). Common core state standards for mathematics.
DBE. (2013). Report on the Annual National Assessment of 2013: Grades 1 to 6 and 9. Pretoria: Department of Basic Education.

Freudenthal, H. (1973). Mathematics as an educational task. Dordrecht: Reidel.

Freudenthal, H. (1983). Didactical phenomenology of mathematical structures. Dordrecht: Reidel.

Guba, EG. (1978). Toward a methodology of naturalistic inquiry in educational evaluation. Monograph 8. Los Angeles: UCLA Center for the Study of Evaluation.

Hoadley, U. (2007). The reproduction of social class inequalities through mathematics pedagogies in South African primary schools. Journal of Curriculum Studies, 39(6), 679-706.

Kazemi, E, \& Stipek, D. (2001). Promoting conceptual thinking in four upper-elementary mathematics classrooms. Elementary School Journal, 102, 59-80.

Kilpatrick, J, Swafford, J, \& Findell, B. (2001). Adding it up: helping children learn mathematics. Washington, D.C.: National Academy Press.

Mason, J. (1989). Mathematical abstraction as the result of a delicate shift of attention. For the Learning of Mathematics, 9(2), 2-8.

Mason, J, Burton, L, \& Stacey, K. (1982). Thinking mathematically. London: Addison-Wesley.

Maturana, H, \& Varela, FJ. (1980). Autopoiesis and cognition: the organization of the living. Boston: Reidel.

Miles, MB, \& Huberman, AM. (1994). Qualitative data analysis: an expanded source, book (2nd ed.). Thousand Oaks, CA: Sage.

Mitchell, J. (1984). Typicality and the case study. In RF Ellen (Ed.), Ethnographic Research: A guide to conduct (pp. 238-241). New York: Academic.

National Council of Teachers of Mathematics. (2000). Principles and standards for school mathematics. Reston, VA: NCTM.

Polya, G. (1962). Mathematical discovery: on understanding, learning and teaching problem-solving. New York: Wiley.

Schifter, D. (2011). Examining the behavior of operations: noticing early algebraic ideas. In M Gamoran Sherin, VR Jacobs, \& RA Philipp (Eds.), Mathematics teacher noticing: seeing through teachers' eyes (pp. 204-220). New York and London: Routledge.

Schoenfeld, AH. (1985). Mathematical problem solving. New York: Academic.

Schoenfeld, AH. (1987). What's all the fuss about metacognition? In AH Schoenfeld (Ed.), Cognitive science and mathematics education (pp. 189-215). Hillsdale, NJ: Lawrence Erlbaum Associates.

Sfard, A. (2008). Thinking as communicating. Cambridge: Cambridge University Press.

Skemp, R. (1976). Relational understanding and instrumental understanding. Mathematics Teaching, 77, 20-26.

Sorto, A, \& Sapire, I. (2011). The teaching quality of mathematics lessons in South African schools. Journal of Education, 51, 1-22.

Taylor, N. (2011). The National School Effectiveness Study (NSES): Summary for the synthesis report. Johannesburg: JET Education Services.

Venkat, H. (2013). Curriculum development minus teacher development ₹ mathematics education. In Z Davis \& S Jaffer (Eds.), Proceedings of the 19th Annual National Congress of the Association for Mathematics Education of South Africa, 24-28th June. Bellville, Cape Town: University of the Western Cape.

Venkat, H, \& Adler, J. (2012). Coherence and connections in teachers' mathematical discourses in instruction. Pythagoras, 33(3), 25-32.

Vinner, S. (1997). The pseudo-conceptual and the pseudo-analytical thought processes in mathematics learning. Educational Studies in Mathematics, 34(2), 97-129.

Watson, A, \& Barton, B. (2011). Teaching mathematics as the contextual application of mathematical modes of enquiry. In T Rowland \& K Ruthven (Eds.), Mathematical knowledge in teaching (pp. 65-82). Dordrecht: Springer.

Watson, A, \& Mason, J. (2006). Seeing an exercise as a single mathematical object: using variation to structure sense-making. Mathematical Thinking and Learning, 8(2), 91-111.

Yackel, E (2001) Explanation, justification and argumentation in mathematics classrooms. In 25th Conference of the International Group for the Psychology of Mathematics Education. Utrecht, The Netherlands, July 12-17 (Vol. 1, pp. 9-24). 